\title{
Serotonin Modulates the Suppressive Effects of Corticosterone on Proliferating Progenitor Cells in the Dentate Gyrus of the Hippocampus in the Adult Rat
}

\author{
Guo-Jen Huang' and Joe Herbert*,' \\ 'Department of Anatomy and Cambridge Centre for Brain Repair, University of Cambridge, UK
}

\begin{abstract}
This series of experiments explores the interaction between corticosterone and serotonin $(5-\mathrm{HT})$ in the regulation of cell proliferation in the dentate gyrus of the adult rat. Intracerebroventricular 5,7-DHT (5,7-dihydroxytryptamine) (either 200 or $300 \mu \mathrm{g}$ ) resulted in highly significant depletion of $5-\mathrm{HT}$ as measured by high performance liquid chromatography in the frontal cortex but had no effect on the number of proliferating cells in the dentate gyrus by measuring 5-bromo-2'-deoxyuridine (BrdU) and Ki-67 cytochemistry. Treatment with PCPA (p-chlorophenylalanine: a tryptophan hydroxylase inhibitor: $300 \mathrm{mg} / \mathrm{kg}$ initially followed by $100 \mathrm{mg} / \mathrm{kg} /$ day) resulted in reduced proliferation as measured by Ki-67 after 3 days treatment, but not by BrdU uptake, and not after 14 days treatment by either method. In addition, injection of corticosterone ( $10-40 \mathrm{mg} / \mathrm{kg} /$ day) for 8 days significantly reduced proliferation in the dentate gyrus, as expected, measured by both BrdU uptake and Ki-67 immunostaining. Adrenalectomized (ADX) rats with a replacement subcutaneous pellet of corticosterone showed reduced proliferation when given additional corticosterone ( $10 \mathrm{mg} / \mathrm{kg} /$ day for 8 days), but this was prevented by 5-HT depletion (i.c.v. 5,7-DHT). Finally, a dose-response study showed that progressive doses of corticosterone $(0-40 \mathrm{mg} / \mathrm{kg} / \mathrm{day})$ in ADX rats resulted in diminished suppression of proliferation in 5-HT-depleted compared with 5-HT-intact rats. These results strongly suggest that 5-HT regulates the sensitivity of proliferating cells in the dentate gyrus to corticosterone

Neuropsychopharmacology (2005) 30, 23 I-24I, advance online publication, I0 November 2004; doi: I0. I038/sj.npp. I 300609
\end{abstract}

Keywords: serotonin; corticosterone; neurogenesis; cell proliferation; hippocampus; dentate gyrus

\section{INTRODUCTION}

The discovery that granule cells in the dentate gyrus of the hippocampus continue to divide to form new neurons throughout adult life in a number of species has radically altered the way we view the organisation and function of this part of the brain (Altman and Das, 1965; Gould et al, 1997; Eriksson et al, 1998). A striking feature of this process is that it is not constant. A number of environmental and endogenous factors alter proliferation rates, which vary (in rodents) from a mean of around 6000-9000 new cells per day (Cameron and McKay, 2001). Two powerful regulating factors are corticosterone and serotonin (5-HT) (Cameron and Gould, 1994; Brezun and Daszuta, 1999).

Glucocorticoids (such as cortisol in man, corticosterone in the rat) markedly suppress proliferation by progenitor cells in the dentate gyrus (Cameron and Gould, 1994).

\footnotetext{
*Correspondence: Professor J Herbert, Department of Anatomy and Cambridge Centre for Brain Repair, University of Cambridge, Downing Sreet, UK, Tel: + 440 1223333748, Fax: 441223 333786,

E-mail: jh24@cam.ac.uk

Received 24 June 2004; revised 17 August 2004; accepted 31 August 2004

Online publication: 6 October 2004 at http://www.acnp.org/citations/ NPPI00604040292/default/pdf
}

Glucocorticoid secretion is highly labile, altering both during the daily light-dark cycle but also in response to stressful physical or psychological events (Timmer, 1962; Ramaley, 1973). Stress itself is known to reduce cell division in the dentate gyrus, although how far this is dependent on the associated stimulation of glucocorticoid secretion from the adrenal cortex is still not absolutely clear (Tanapat et al, 1999).

The hippocampus has a rich serotoninergic innervation (McQuade and Sharp, 1997) and several studies have claimed that altering 5-HT (serotonin) can itself change the number of dividing granule cells in the dentate gyrus (Brezun and Daszuta, 1999, 2000; Banasr et al, 2001). Lowering 5-HT levels reduced neurogenesis, whereas increasing it by treatment with drugs - such as specific 5HT reuptake inhibitors (SSRIs) - stimulated neurogenesis (Malberg et al, 2000). Activation of 5-HT1A receptors by the agonist 8-OH-DPAT has been reported to increase cell proliferation in the dentate gyrus (Santarelli et al, 2003).

The interaction between 5-HT and corticosterone on adult neurogenesis has not been investigated so far. Yet, there is much evidence to suggest that such an interaction might exist. There is a considerable evidence that procedures that alter 5-HT activity also change corticosterone levels: for example, depleting 5-HT or giving receptor 
agonists alters plasma corticosterone levels (Harbuz et al, 1993; Chung et al, 1999; Hemrick-Luecke SK, 2002). Corticosterone may also have a more direct action on 5HT in the brain (Mueller and Beck, 2000; Bush et al, 2003; Gartside et al, 2003; Leitch et al, 2003) such as decreasing 5HT1A receptor expression in the dentate gyrus (Meijer and de Kloet, 1994; Fairchild et al, 2003). Adrenalectomy (ADX), which stimulates neurogenesis, increases 5-HT1A receptor binding and mRNA expression in the hippocampus (Chalmers et al, 1993; Kuroda et al, 1994). Tryptophan hydroxylase, the principal enzyme regulating the synthesis of 5-HT, is controlled by adrenal corticosterone (Azmitia et al, 1993; Clark and Russo, 1997). Stress alters the response of hippocampal neurons to 5-HT (van Riel et al, 2003). There is also a converse interaction: 5-HT may regulate the actions of corticosterone on the brain, although this has been less well studied. For example, drugs acting on 5-HT (eg SSRIs) modulate the activity of the corticosterone receptor (Pariante et al, 2001).

Neurogenesis in the adult hippocampus has been linked with depression (Malberg and Duman, 2003). Cortisol dysregulation is known to be a feature of current depression (Sachar, 1975; Murphy, 1991), and individual differences in the levels of morning cortisol are a risk factor for subsequent major depressive disorder (MDD) in both adult women and adolescents (Goodyer et al, 2000; Harris et al, 2000). Polymorphisms in the 5-HT transporter predispose to the development of depression following adverse life events (Caspi et al, 2003), and the latent period (3-4 weeks) preceding the therapeutic response to antidepressants may be related to the increased formation of new neurons in the dentate gyrus - which takes about the same time (Malberg et al, 2000).

These considerations prompted us to investigate the interaction between corticosterone and central 5-HT activity in the regulation of neurogenesis in the adult rat's hippocampus. First, we carried out a series of experiments to determine the effects of reducing central 5-HT levels on cell proliferation in the dentate gyrus. Then, we investigated the interaction between altered 5-HT and the sensitivity of the dentate gyrus to administered corticosterone. Our results show that reducing $5-\mathrm{HT}$ in the brain alters the sensitivity of cell proliferation to both endogenous and administered corticosterone. In both sets of experiments, we used two methods of assessing proliferation: intraperitoneal 5-bromo-2'-deoxyuridine (BrdU), which labels dividing cells by substituting for thymidine (Wato et al, 1993), and Ki-67, an endogenous antigen expressed by dividing cells (Scholzen and Gerdes, 2000; Kee et al, 2002). The latter obviates the possibility that reducing central 5HT also changes access to the brain by systemic BrdU.

\section{MATERIALS AND METHODS}

\section{Animals}

All procedures were carried out under Home Office (UK) licence. Lister Hooded male rats (Harlan UK), weighing around $250-300 \mathrm{~g}$ at the beginning of the experiment, were used. They were housed 3-4 per cage on reversed 12-h light: 12 -h dark cycles (lights off at 1100 hours). Ambient temperature was maintained at $21 \pm 2{ }^{\circ} \mathrm{C}$. Food and water were available ad libitum. All adrenalectomized animals were given free access to both tap water and $0.9 \%$ saline.

Experiment 1: The effect of central 5-HT depletion by 5,7DHT (5,7-dihydroxytryptamine) on proliferation in the dentate gyrus. Three groups of intact male rats $(n=8$ in each group) were all pretreated with i.p. injections of $15 \mathrm{mg} /$ $\mathrm{kg}$ nomifensine maleate (Sigma, UK) and $20 \mathrm{mg} / \mathrm{kg}$ desipramine (Sigma, UK) 20 min before the surgery to prevent the effect of 5,7-DHT on tissue levels of dopamine (DA) and noradrenaline (NA). Surgery was performed under isoflurane anaesthesia. Two groups received bilateral injections (i.c.v.) of either 300 or $200 \mu$ g of 5,7-DHT free base (Fluka, UK) in a volume of $10 \mu \mathrm{l}$ infused over $4 \mathrm{~min}$ into the lateral ventricle using a $10 \mu \mathrm{l}$ syringe $(5 \mu \mathrm{l} /$ ventricle $)$ under stereotaxic guidance (AP $-0.8 \mathrm{~mm}, \mathrm{ML} 1.5 \mathrm{~mm}$ from bregma and DV $-4.2 \mathrm{~mm}$ from dura, with all the measurements taken with the incisor bar set at $-3.3 \mathrm{~mm})$. Animals of the sham group received vehicle $(0.1 \mathrm{M}$ ascorbate dissolved in $0.9 \%$ saline). After infusion, the cannula remained in place for a further $4 \mathrm{~min}$. All animals were monitored to ensure that food and water intake was normal after surgery (Chung et al, 1999).

At 14 days after the surgery, all rats were injected with a single dose of BrdU (200 mg/kg, Sigma, UK) dissolved in saline (Cameron and McKay, 2001). After 24h, they were terminally anaesthetized with an overdose of pentobarbitone sodium $(0.5 \mathrm{ml}, 200 \mathrm{mg} / \mathrm{ml}$; Merial Animal Health Ltd, UK) intraperitoneally, and a blood was sample taken within $5 \mathrm{~min}$ of induction for corticosterone assay. A sample of prefrontal cortex (PFC) was taken for 5-HT, NA, and DA determination by an high performance liquid chromatography (HPLC)-electrochemical method. Then, these animals were perfused through the ascending aorta with about $50 \mathrm{ml} 0.9 \%$ saline followed by about $200 \mathrm{ml} 4 \%$ paraformaldehyde ( $\mathrm{pH} 7.4$ ) immediately.

Experiment 2: The effect of acute (3 day) 5-HT depletion by PCPA. Two groups of six intact rats were given daily injections for 3 days of either PCPA ( $p$-chlorophenylalanine) (Sigma, UK; $300 \mathrm{mg} / \mathrm{kg}$ dissolved in saline, followed by $100 \mathrm{mg} / \mathrm{kg}$ for another 2 days) or vehicle i.p. All rats were injected with a single dose of BrdU (200 mg/kg) $24 \mathrm{~h}$ after the last PCPA (or saline) injection and blood and brain samples taken as above $2 \mathrm{~h}$ later.

Experiment 3: The effect of chronic (14 day) 5-HT depletion by PCPA. Two groups of six intact rats were treated as follows. The control group was injected with saline (once daily, i.p. at 1100 hours). The other group was depleted of 5-HT by PCPA (once daily, initially $300 \mathrm{mg} / \mathrm{kg}$, followed by $100 \mathrm{mg} / \mathrm{kg}$, i.p.). All injections were carried out for 14 days (Tagliaferro et al, 1997). The last PCPA (or saline) injection and a single dose of BrdU $(200 \mathrm{mg} / \mathrm{kg})$ were given $24 \mathrm{~h}$ prior to killing. Blood and brain samples were taken as above.

Experiment 4: The effect of corticosterone on proliferation in the dentate gyrus. Three groups of intact male rats ( $n=7$ in each group) were used. Corticosterone (Sigma, UK) was suspended in peanut oil (Sigma, UK). Groups were 
given a daily injection of either corticosterone $(40 \mathrm{mg} / \mathrm{kg}$, or $10 \mathrm{mg} / \mathrm{kg}$ ) or oil for 8 days. BrdU was administered intraperitoneally at a dose of $50 \mathrm{mg} / \mathrm{kg}$ daily given over the last 4 days. At $24 \mathrm{~h}$ after the last injection of BrdU, $6 \mathrm{~h}$ after the last corticosterone injection, the animals were killed and blood and brain samples taken.

Experiment 5: The effect of 5-HT depletion on the response to additional corticosterone in adrenalectomized, corticosterone-clamped rats. Four groups of five rats were used. All animals were adrenalectomized, after which they were implanted with a subcutaneous pellet containing 25\% corticosterone/cholesterol (weight approximately $200 \mathrm{mg}$ ). Subsequent to adrenalectomy, half of the animals in each group were depleted of 5-HT by i.c.v. 5,7DHT (200 $\mu \mathrm{g}$ as above) and the other half received saline i.c.v. infusions. After 7 days, half of each group received additional corticosterone $(10 \mathrm{mg} / \mathrm{kg} /$ day for a further 8 days). They were injected daily with $\mathrm{BrdU}$ ( $50 \mathrm{mg} / \mathrm{kg}$ ip) for the last 4 days of the experiment and killed $24 \mathrm{~h}$ later. Blood was taken for corticosterone assay $6 \mathrm{~h}$ after the last corticosterone injection, and the rats then perfused with saline and fixative as above.

Experiment 6: The effect of 5-HT depletion on the response to incremental doses of corticosterone in adrenalectomized rats. A total of 50 rats were used in this experiment. In all, 25 rats were either depleted of 5-HT by i.c.v. 5,7-DHT $(200 \mu \mathrm{g})$, or were sham operated. After 1 week, all animals were bilaterally adrenalectomized, and equal number of animals from each surgical group were given corticosterone injections $(0,3,10,20$, or $40 \mathrm{mg} / \mathrm{kg}$, five each group) for 8 days, beginning $24 \mathrm{~h}$ after adrenalectomy. It is to be noted that animals not given replacement corticosterone (ie $0 \mathrm{mg} / \mathrm{kg} /$ day) did not survive after 5-HT depletion and so do not figure in the results. At $24 \mathrm{~h}$ after the last injection of BrdU, and $6 \mathrm{~h}$ after the last corticosterone injection, the animals were killed and blood samples taken.

\section{Brain Fixation and Histology}

Rats were anaesthetized with an overdose of pentobarbitone (Merial Animal Health Ltd, UK). The sample of PFC was taken after overdose pentobarbitone injection and before perfusion and fixation. The chest was opened, and a cannula inserted in the left ventricle. Rats were perfused with saline (about $50 \mathrm{ml}$ ) followed by about $100 \mathrm{ml}$ of $4 \%$ paraformaldehyde ( $\mathrm{pH} 7.4$, Fisher, UK). The brain was removed, postfixed for $4 \mathrm{~h}$, and then immersed in 30\% sucrose KPBS overnight. Coronal sections were cut through the entire dentate gyrus at $40 \mu \mathrm{m}$ and sections taken into a bath of antifreeze (1:1:2= glycol: ethylene glycol: $0.1 \mathrm{M} \mathrm{PBS})$.

\section{Immunohistochemistry}

For BrdU staining, sections were mounted onto polylysinecoated slides (BDH, UK), dried overnight, incubated in $0.01 \mathrm{M}$ citric acid for $10 \mathrm{~min}$ at $90^{\circ} \mathrm{C}$, incubated in $3 \% \mathrm{H}_{2} \mathrm{O}_{2}$ for $10 \mathrm{~min}$, digested in trypsin $250(0.025 \%$ in Tris buffer containing $0.1 \% \mathrm{CaCl}_{2}$ ) for $10 \mathrm{~min}$, denatured in $2 \mathrm{~N} \mathrm{HCl}$ for $30 \mathrm{~min}$ at $37^{\circ} \mathrm{C}$, rinsed, incubated overnight at room temperature in mouse monoclonal antibody raised against BrdU (Novocastra; 1:200 in 0.3\% Triton, 0.2\% normal horse serum). The slides were rinsed and taken through a mouse IgG ABC kit procedure (Vector), rinsed, and reacted for $10 \mathrm{~min}$ with a Sigma DAB tablet. The slides were then rinsed again, dehydrated, and cover slipped under DPX.

For Ki-67 staining, sections were mounted, dried overnight, incubated in $0.01 \mathrm{M}$ citric acid for $40 \mathrm{~min}$ at $90^{\circ} \mathrm{C}$, incubated in $3 \% \mathrm{H}_{2} \mathrm{O}_{2}$ for $10 \mathrm{~min}$, rinsed, incubated overnight at room temperature in mouse monoclonal antibody against Ki-67 (Novocastra; $1: 100$ in $0.3 \%$ Triton, $0.2 \%$ normal horse serum). They were then taken through the mouse IgG ABC kit procedure, rinsed, and reacted for 10 min with a Sigma DAB tablet. The sections were then counterstained with cresyl violet, dehydrated, and coverslipped under DPX.

For 5-HT staining, sections were mounted, dried overnight, incubated in $0.01 \mathrm{M}$ citric acid for $10 \mathrm{~min}$ at $90^{\circ} \mathrm{C}$, incubated in $3 \% \mathrm{H}_{2} \mathrm{O}_{2}$ for $10 \mathrm{~min}$, rinsed, incubated overnight at room temperature in rabbit antibody against 5-HT (Immunostar; 1:2000 in 0.3\% Triton, 0.2\% normal goat serum), then taken through the standard staining procedure described above.

\section{Corticosterone Assays}

Blood samples were collected by cardiac puncture after overdose of pentobarbitone and were heparinized (syringe rinsed with heparin; CP Pharmaceuticals, UK), centrifuged at 3000 r.p.m. for $15 \mathrm{~min}$. Plasma was collected and stored at $-20^{\circ} \mathrm{C}$ until assay. Corticosterone was measured by radioimmunoassay using a validated procedure (Chung et al, 1999). Coefficients of variation were: intra-assay, $4.75 \%$; inter-assay, $8.49 \%$.

\section{HPLC}

Samples were taken from the PFC before perfusion, snap frozen in dry ice and stored at $-70^{\circ} \mathrm{C}$. They were thawed and weighed, 10 volumes of the homogenization solution ( $0.4 \mathrm{M}$ perchloric acid, $0.1 \%$ sodium metabisulphite, $0.02 \%$ cysteine, and $0.01 \%$ EDTA) was added, homogenized on an ice bath and centrifuged at 15000 r.p.m. for $20 \mathrm{~min}$. Supernatants were collected and the concentrations of 5HT, 5-hydroxyindole-acetic acid (5-HIAA), NA, DA, and dihydroxyphenylacetic acid (DOPAC) were measured using HPLC with electrochemical detection. The concentrations of these neurotransmitters are expressed as ng per mg of wet weight.

\section{Quantification}

All slides were randomized and coded prior to quantitative analysis. Slides were examined under $\times 40$ objective, and BrdU- and Ki-67-labelled cells were counted on every eighth section through the entire rostrocaudal extent of granule cell level bilaterally (ie 12 sections per animal). BrdU/Ki-67 cells in all focal planes through the $40 \mu \mathrm{m}$ section were included. The number of cell counted from the raw data was then multiplied by eight to obtain an estimate of the total number of Ki-67- or BrdU-positive cells in this sample of the dentate gyrus. 


\section{Statistical Analysis}

Grouped data were analyzed by one or two-way ANOVA or Student's $t$-test, both with logarithmic transformation if the variances were not homogeneous. In experiment 6 , the effects of corticosterone and 5-HT depletion on BrdU and Ki-67 cell counts were examined using linear regression models with main effects corticosterone (dose) and 5-HT depletion status (sham, depleted).

\section{RESULTS}

Experiment 1: The Effect of 5-HT Depletion by i.c.v. 5,7-DHT on Proliferation in the Dentate Gyrus

I.c.v. 5,7-DHT treatment resulted in highly significant depletions in 5-HT and 5-HIAA in the PFC $(\mathrm{F}=117.7$, $p<0.0001$ and $\mathrm{F}=57.18, p<0.0001$, respectively). Compared to control levels, the neurotoxin reduced 5-HT by $80 \%$ overall (see Table 1 ). In addition, 5 -HT immunostaining in the hippocampus showed absence of stained axons, in contrast to the profuse staining seen in the control brains (see Figure 1). There were no changes in NA, DA, or DOPAC (data not shown). Despite the reduced 5-HT, there were no significant differences in either BrdU- or Ki-67labelled cells within these three groups $(\mathrm{F}=1.86, \mathrm{NS}$, $\mathrm{F}=0.38$, NS, respectively) (see Figure 2). However, as expected, 5-HT-depleted animals showed significantly higher plasma corticosterone than sham-operated rats $(\mathrm{F}=39.6$, $p<0.0001$ ) (see Table 1).

\section{Experiment 2: The Effect of Acute (3 day) 5-HT Depletion by PCPA}

PCPA induced a highly significant reduction in both 5-HT and 5-HIAA content in the PFC (5-HT, $p<0.0001,5$-HIAA, $p<0.0001$ ) (see Table 1). Overall, 5-HT was depleted by $95 \%$. However, there was no significant difference in plasma corticosterone levels $(t=1.59, p=0.14)$, even though mean levels in the PCPA group were almost twice of those in controls (see Table 1). Although BrdU-labelled cell counts were lower in the PCPA-treated group, this was not significant $(t=1.88, p=0.09)$. However, the number of Ki-67-labelled cells was significantly decreased in PCPAtreated rats $(t=3.5, p<0.01)$ (see Figure 3 ).

\section{Experiment 3: The Effect of Chronic (14 days) 5-HT Depletion by PCPA}

PCPA had a highly significant effect on reducing brain 5-HT levels (5-HT, $t=23.5, \quad p<0.0001 ; \quad 5$-HIAA, $t=15.2$, $p<0.0001$ ) (see Table 1). Despite these results, there were no significant alterations in either BrdU- or Ki-67-labelled cell counts in this experiment (BrdU, F $=0.74$, NS; Ki-67, $t=0.55$, NS) (see Figure 4). Immunostained sections for 5HT confirmed that there was no 5-HT-stained fibers detectable in the dentate gyrus after PCPA treatment (see Figure 4). There were no significant differences in plasma corticosterone levels $(t=0.9$, NS) (see Table 1 ).

\section{Experiment 4: The Effect of Corticosterone on Cell Proliferation in the Dentate Gyrus}

As expected, corticosterone markedly reduced the number of labelled cells in the dentate gyrus (see Figure 5). There were highly significant effects on both BrdU- $(F=39.2$, $p<0.0001)$ and Ki-67-labelled cells $(\mathrm{F}=101.5, p<0.0001)$. The three treatments also resulted in significantly different plasma corticosterone levels $(\mathrm{F}=143.3, p<0.0001)$.
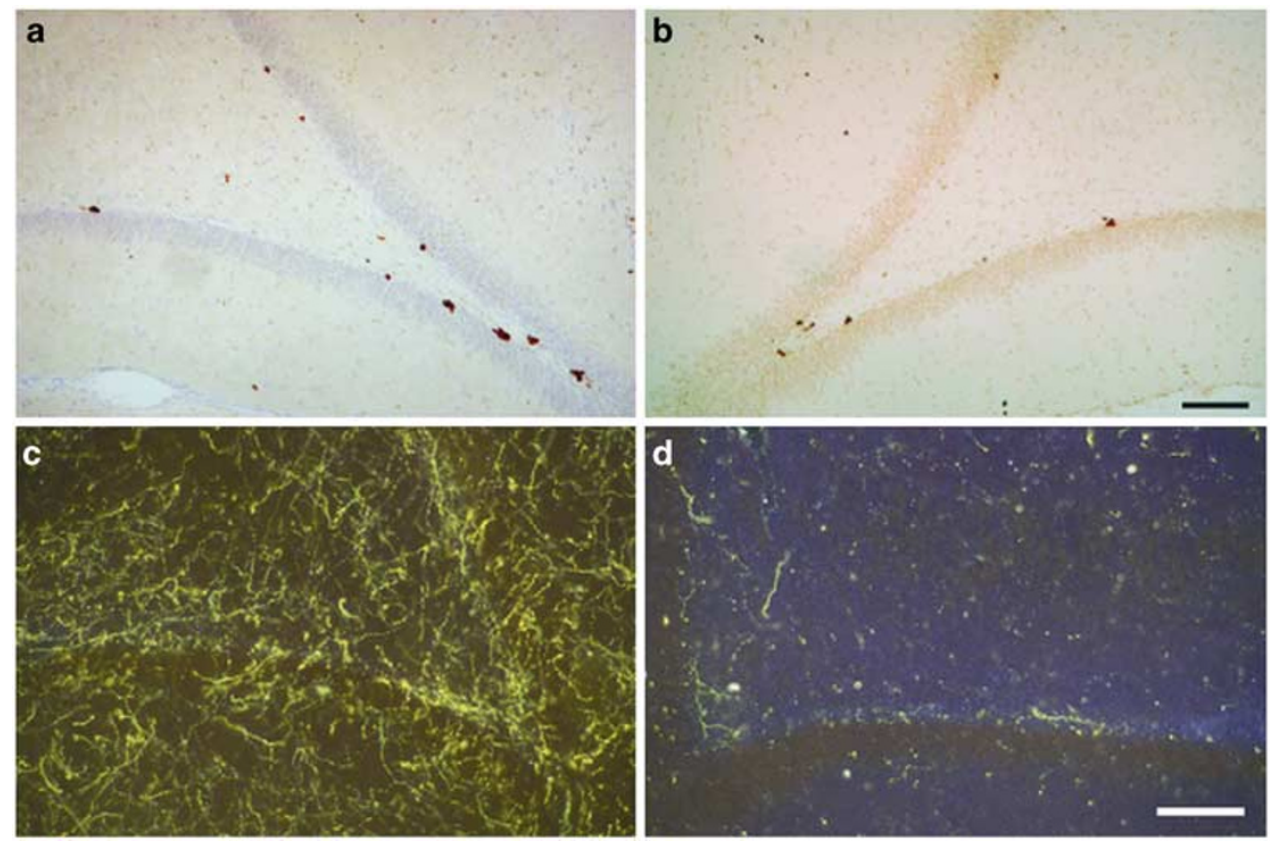

Figure I (a, b) Image from the dentate gyrus stained for Ki-67 (a) and BrdU (b). (c, d) Immunostaining for 5-HT in intact (c) and 5,7-DHT (200 $\mu$ g)treated (d) animals 15 days after i.c.v. surgery. Scale bar $=0.1 \mathrm{~mm}$. 
a

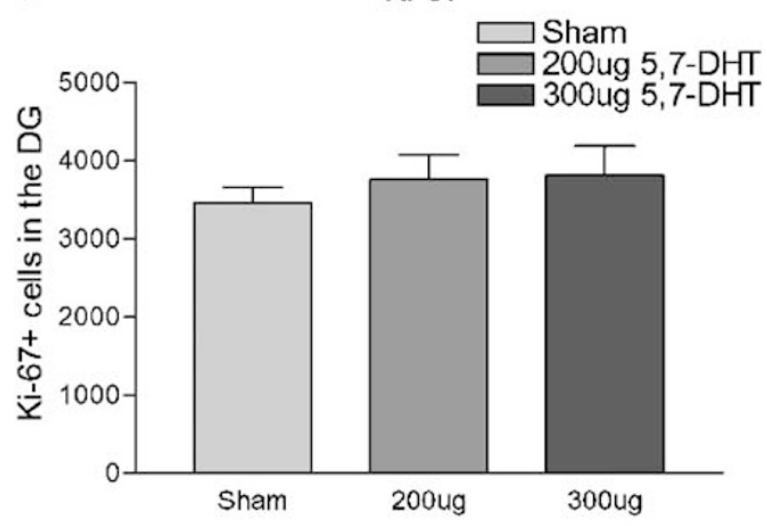

b

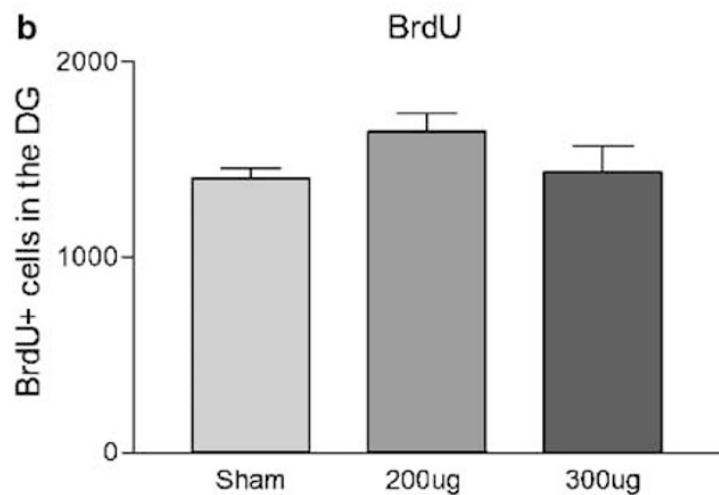

Figure 2 Effect of depleting 5-HT by i.c.v. 5,7-DHT (200 $\mu \mathrm{g}$ or $300 \mu \mathrm{g})$ for 15 days on the numbers of (a) Ki-67- and (b) BrdU-labelled cells in the dentate gyrus. Values are means \pm SEM in this and subsequent figures.

\section{Experiment 5: The Effect of 5-HT Depletion on the Response to Additional Corticosterone Treatment in Adrenalectomized, Corticosterone-Clamped Rats}

5-HT in rats treated with i.c.v. 5,7-DHT was highly reduced as shown by $5-\mathrm{HT}$ immunostaining (not shown). As expected, in sham-infused rats, treatment of ADX rats with additional corticosterone $(10 \mathrm{mg} / \mathrm{kg} /$ day $)$ on top of the 'baseline' pellet decreased both BrdU and Ki-67 staining (BrdU, $\mathrm{F}=4.05, p<0.01 ; \mathrm{Ki}-67, \mathrm{~F}=5.25, p<0.001)$ compared with those not receiving extra corticosterone (see Figure 6). Labelled cell counts were no different in 5-HTdepleted rats and sham-infused ones under basal conditions (ie with an implanted corticosterone pellet only). However, while additional corticosterone decreased cell counts in sham-infused animals, they had no effect in 5-HT-depleted ones (BrdU, $t=0.38, p>0.05$; Ki-67, $t=0.14, p>0.05$ ) (see Figure 6). The interaction between corticosterone and 5-HT depletion was therefore significant, both for $\mathrm{BrdU}(\mathrm{F}=5.2$, $p<0.02)$ and for Ki-67 $(\mathrm{F}=13.6, p<0.002)$. Surprisingly, basal plasma corticosterone was significantly higher in 5HT-depleted than sham-operated rats with a corticosterone pellet $(p<0.03)$ (see Table 1).

\section{Experiment 6: The Effect of 5-HT Depletion on the Response to Incremental Doses of Corticosterone in Adrenalectomized Rats}

Animals depleted of 5-HT by 5,7-DHT and adrenalectomized but not given corticosterone did not survive. Thus, there are no groups receiving $0 \mathrm{mg} / \mathrm{kg}$ corticosterone in the data set. 5-HT levels were reduced in the dentate gyrus by i.c.v. 5,7-DHT (as in Experiment 1: see Figure 1). Figure 7 shows the number of BrdU- and Ki-67-labelled cells in the dentate gyrus after each dose of corticosterone. The overall effect of corticosterone was confirmed by linear regression (BrdU, $\mathrm{F}=44.8, p<0.0001$; Ki-67, $\mathrm{F}=52.5, p<0.0001)$. In the sham-depleted rats, there was a progressive decrease in proliferating cells over the first three doses $(3,10$, and $20 \mathrm{mg} / \mathrm{kg}$ ), but an apparent 'floor' effect at the highest one $(40 \mathrm{mg} / \mathrm{kg})$. In the 5-HT depleted rats, there was a progressive decrease over the dose range of corticosterone used. The figure shows that at each dose of corticosterone, except the highest one, the numbers of labelled cells were higher in the 5-HT-depleted rats than in the controls. Pairwise comparisons confirmed that there were significant differences between the two groups at $10 \mathrm{mg} / \mathrm{kg}(\mathrm{BrdU}$, $t=3.84, p<0.01 ; \mathrm{Ki}-67, t=3.27, p<0.02)$ and $20 \mathrm{mg} / \mathrm{kg}$ (BrdU, $t=3.21, p<0.02$; Ki-67, $t=3.15, p<0.02$ ); at $3 \mathrm{mg} / \mathrm{kg}$ group, there was a nonsignificant but clear trend (BrdU, $t=1.89, p=0.1$; Ki-67, $t=1.57, p=0.15)$, but no difference at $40 \mathrm{mg} / \mathrm{kg}$ group (BrdU, $t=0.12, p=0.9 ; \mathrm{Ki}-67, t=1.80$, $p=0.1$ ). Normalizing the data, by expressing 5 -HT-depleted animals as a percentage of the corresponding sham group, showed a consistent excess of labelled cells in the 5-HTdepleted group at each of the three lower doses of corticosterone. The largest difference was observed at $20 \mathrm{mg} / \mathrm{kg}$. The data are as follows: $(3,10,20,40 \mathrm{mg} / \mathrm{kg}$, respectively) Ki-67: 131, 151, 204, and 125\%; BrdU: 145, 169, 229, and 97\% (see Figure 7).

\section{DISCUSSION}

Two markers were used for cell proliferation in these experiments: BrdU and Ki-67. It was essential to use $\mathrm{Ki}-67$ to exclude the possibility that $\mathrm{BrdU}$ incorporation into brain cells might be influenced by corticosterone or 5-HT depletion. Although Ki-67 labels cells throughout the whole cell cycle, whereas BrdU labels them during the S-phase, the exact numerical equivalence between the two methods will depend on the details of BrdU administration and survival time. For this reason, we have not compared the two methods directly, but analysed all data within each technique. The important fact is that the two techniques gave essentially similar results.

Depleting 5-HT by i.c.v. 5,7-DHT had no effect on cell proliferation 2 weeks after surgery. This was not in accordance with previous reports (Brezun and Daszuta, $1999,2000)$. There are possibly important differences in the methods used in these experiments and in those reported here. The first of these studies used shorter treatment with PCPA or injected 5,7-DHT directly into the raphe nuclei, the second also depleted 5-HT by injecting 5,7-DHT directly into the raphe after a longer period of treatment, and both studies used female Wistar rats. Proliferating cells were counted 1 week after treatment in the first experiment, 60 days in the second, but in our cases after 3 and 14 days. In addition, there are recent reports to suggest that different strain or gender of animals show varied basal levels of neurogenesis (Tanapat et al, 1999; Kempermann and Gage, 2002). Whether these factors could affect the response 
Table I Levels of 5-HT and 5-HIAA in the Prefrontal Cortex (PFC) and Plasma Corticosterone in Experiments I-6

\begin{tabular}{|c|c|c|}
\hline & Sham lesion & $200 \mu \mathrm{g}$ 5,7-DHT \\
\hline \multicolumn{3}{|l|}{ Experiment 1} \\
\hline 5-HT (nM) & $2162 \pm 144.3$ & $429.9 \pm 75.23 * * * *$ \\
\hline 5-HIAA (nM) & $505.3 \pm 65.44$ & $8.14 \pm 1.90 * * *$ \\
\hline Corticosterone $(\mathrm{ng} / \mathrm{ml})$ & $107.9 \pm 10.4 \mid$ & $218.6 \pm 23.65$ ***** \\
\hline \multicolumn{3}{|l|}{ Experiment 2} \\
\hline & Saline & $\begin{array}{c}\text { PCPA }(300 \mathrm{mg} / \mathrm{kg} \\
\text { followed by } 100 \mathrm{mg} / \mathrm{kg} \text { for } \\
2 \text { days })\end{array}$ \\
\hline 5-HT (nM) & $1832 \pm 234.2$ & $100.5 \pm 11.52$ ****** \\
\hline 5-HIAA (nM) & $1470 \pm 130.7$ & $4 \pm 0.18$ 米米 \\
\hline Corticosterone $(\mathrm{ng} / \mathrm{ml})$ & $93.83 \pm 19.99$ & $146.2 \pm 26.09$ \\
\hline \multicolumn{3}{|l|}{ Experiment 3} \\
\hline & Saline & $\begin{array}{c}\text { PCPA }(300 \mathrm{mg} / \mathrm{kg} \\
\text { followed by } 100 \mathrm{mg} / \mathrm{kg} \text { for } \\
13 \text { days })\end{array}$ \\
\hline 5-HT (nM) & $1079 \pm 49.29$ & $28.67 \pm 4.26 * * * *$ \\
\hline 5-HIAA (nM) & $259.4 \pm 16.85$ & $27.17 \pm 1.74$ ***** \\
\hline Corticosterone $(\mathrm{ng} / \mathrm{ml})$ & $156.7 \pm 16.99$ & $|36.5 \pm| 4.5 \mid$ \\
\hline
\end{tabular}

Experiment 4

Sham (oil)

Corticosterone $(\mathrm{ng} / \mathrm{ml})$

Experiment 5

Corticosterone $(\mathrm{ng} / \mathrm{ml})$

Sham (oil)

$51.8 \pm 9.46$
10 mg/kg corticosterone $324.2 \pm 22.76$ ****
$300 \mu \mathrm{g}$ 5,7-DHT

$460 \pm 63.26 * * * *$

$12.13 \pm 1.60 * * *$

$354.8 \pm 22.17$ ***** $\mathbf{4 0} \mathbf{~ m g / k g}$ corticosterone
$476.7 \pm 24.34 * * * * * 6$

Depletion (oil)

$204.2 \pm 55.69$

\section{Depletion ( $10 \mathrm{mg} / \mathrm{kg}$ corticosterone)}

$311.5 \pm 39.6$

Experiment 6

Plasma corticosterone (ng/ml)

Treatment
$3 \mathrm{mg} / \mathrm{kg} /$ day corticosterone
$10 \mathrm{mg} / \mathrm{kg} /$ day
$20 \mathrm{mg} / \mathrm{kg} /$ day
$40 \mathrm{mg} / \mathrm{kg} /$ day

\begin{tabular}{cc}
\multicolumn{2}{c}{ Plasma corticosterone $(\mathbf{n g} / \mathbf{m l})$} \\
\hline Sham & Depletion \\
$120.5 \pm 20.23$ & $265 \pm 34.06 *$ \\
$215.8 \pm 22.69$ & $356.2 \pm\left. 40.5\right|^{*}$ \\
$316.5 \pm 62.84$ & $368.6 \pm 41.01$ \\
$419.6 \pm 31.37$ & $408.8 \pm 44.5$
\end{tabular}

Corticosterone was detected $6 \mathrm{~h}$ after the last corticosterone injection in Experiments $4-6(* p<0.05, * * * p<0.00$ l compared to control).

to 5-HT depletion on proliferation is still unknown. Electrochemical analysis of the PFC showed that our 5-HT-depleting procedure to have been very effective; it is likely that 5-HT was similarly depleted in the hippocampus since 5-HT immunostaining showed apparent absence of 5-HT-stained fibers. In addition, in previous experiments, we have shown that 5,7-DHT depletes 5-HT similarly in both PFC and hippocampus (Chung et al, 1999, 2000). However, it was striking that these null effects occurred in the present study despite considerably increased plasma corticosterone in 5,7-DHT-treated rats. The changes in corticosterone levels after 5-HT depletion agreed with some previous findings (Harbuz et al, 1993; Chung et al, 1999), but not others (Temel et al, 2003). It seemed remarkable that cell proliferation remained unaltered in the face of such marked increases in blood corticosterone levels.

Since we observed no effect of 5-HT depletion by 5,7-DHT on cell proliferation, the next experiments explored alternative approaches to reduce brain 5-HT levels. In Experiment 2, we used an acute 3-day treatment with PCPA, a 5-HT synthesis inhibitor, to reduce overall 5-HT levels. Proliferation in the dentate gyrus was significantly reduced as demonstrated by Ki-67 counts, which agrees with a previous report (Banasr et al, 2001). However, despite an 
evident trend, we were not able to confirm this using BrdU; it may be that using larger numbers of rats (six per group in this study) might have improved levels of significance.
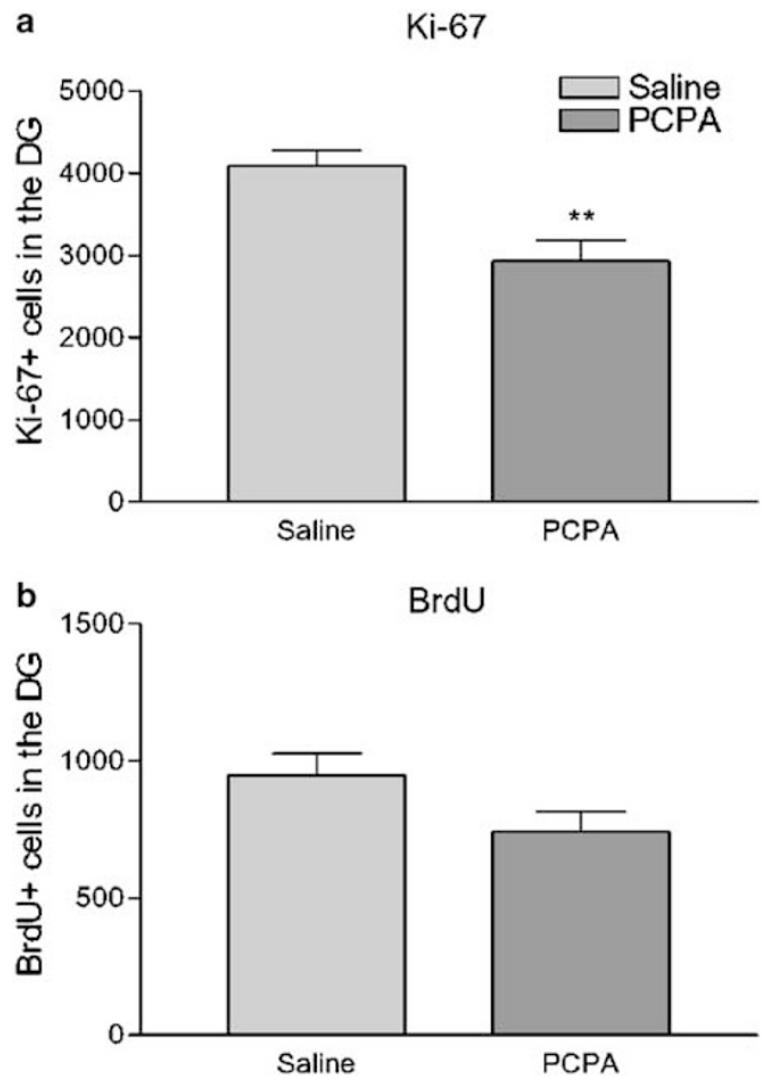

Figure 3 Effect of depleting 5-HT by PCPA (3 days treatment, $300 \mathrm{mg} /$ $\mathrm{kg}$ followed by $100 \mathrm{mg} / \mathrm{kg}$ for 2 days) on the numbers of (a) Ki-67- and (b) BrdU-labelled cells in the dentate gyrus. (*** $p<0.01$ vs control).
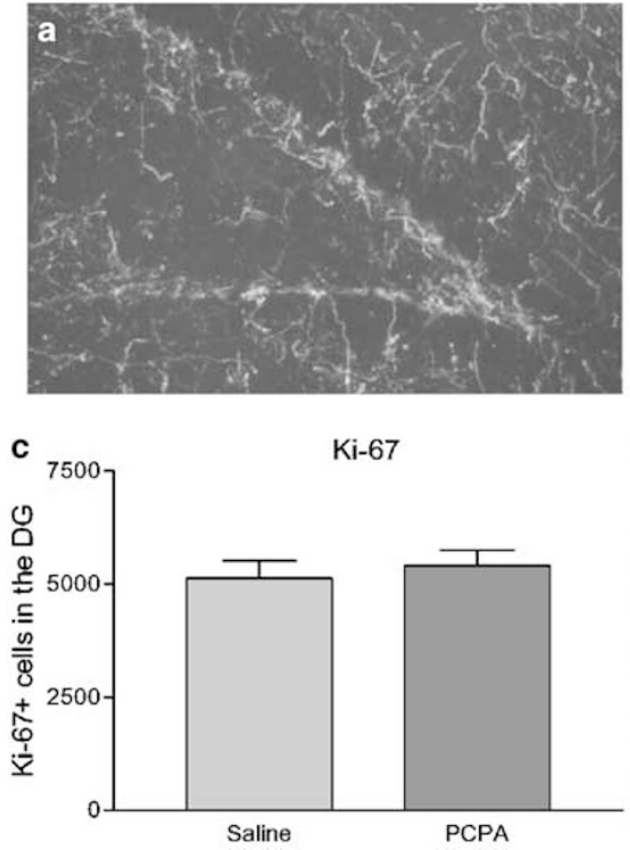

Figure 4 (a, b) 5-HT immunostaining in the dentate gyrus from rats treated with vehicle (a), PCPA (b) for I 4 days. Scale bar =0.I mm. (c, d) (c) Ki-67and (d) BrdU-labelled cell counts following vehicle or PCPA (300 mg/kg followed by $100 \mathrm{mg} / \mathrm{kg}$ for 13 days).
Effects of PCPA on plasma corticosterone were not clearcut: despite an apparent increase as in Experiment 1, this was not significant.
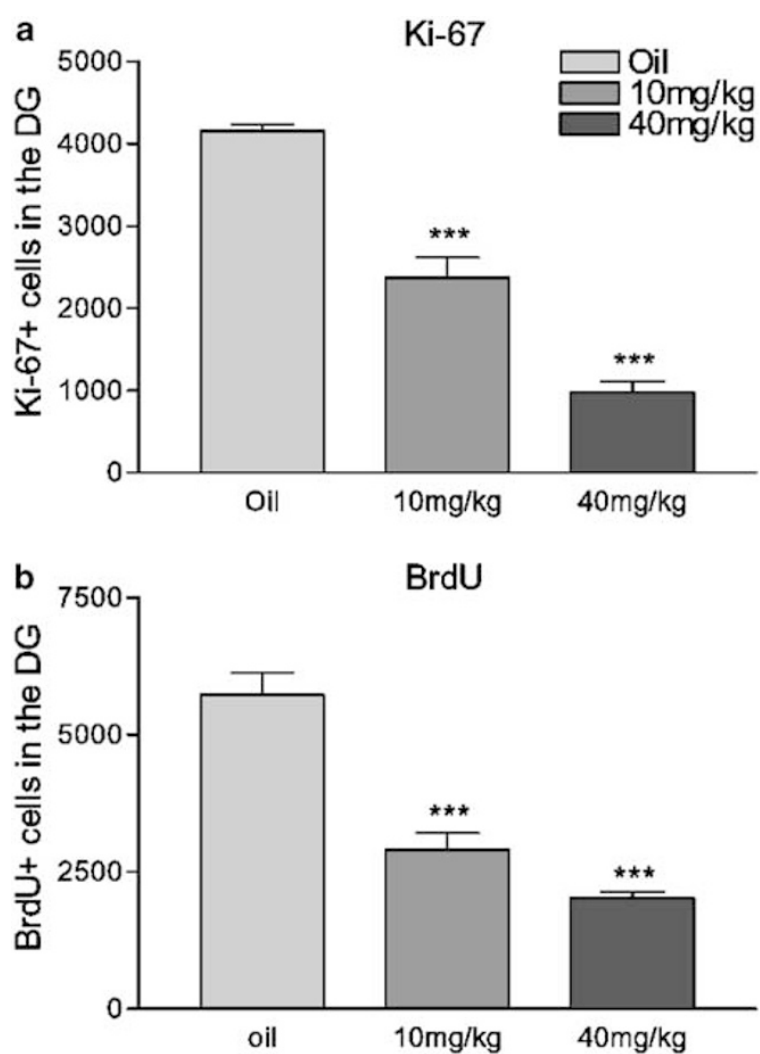

Figure 5 Effect of daily injections of corticosterone (oil, $10 \mathrm{mg} / \mathrm{kg}$, or $40 \mathrm{mg} / \mathrm{kg}$ ) for 8 days on the numbers of (a) Ki-67- and (b) BrdU-labelled cell counts in the dentate gyrus. (**** $p<0.00$ I vs control).
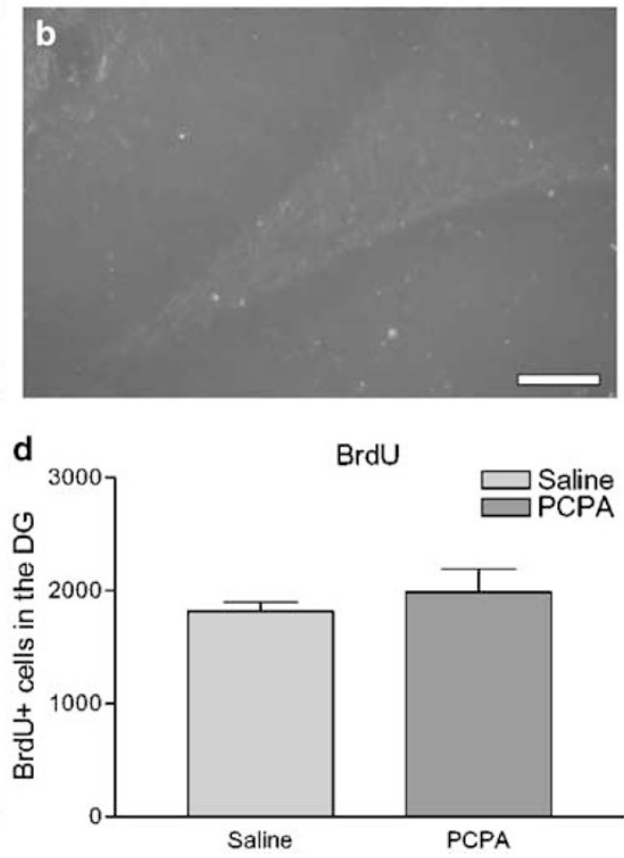
a
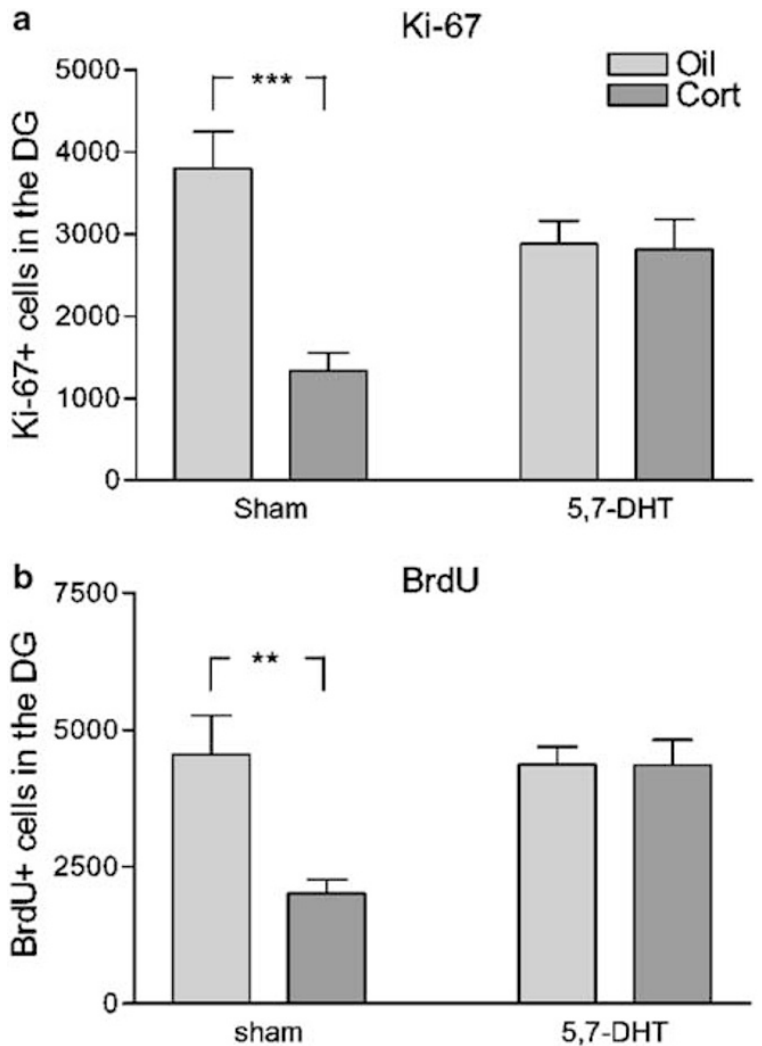

Figure 6 (a) Ki-67- and (b) BrdU-labelled cell counts 15 days after in 5 HT-depleted (i.c.v. 5,7-DHT) or sham-operated rats, which were all bilaterally adrenalectomized (ADX) and implanted with a subcutaneous basal level corticosterone pellet. Half of them were injected with additional oil; the others were given additional corticosterone $(10 \mathrm{mg} / \mathrm{kg})$ for the last 8 days (*** $p<0.01$, **** $p<0.001$ compared to respective controls).
Since the two approaches to 5-HT depletion yielded contradictory results on cell proliferation, this led us to carry out a 14-day treatment with PCPA (the same treatment period as in Experiment (1) to see if the effect of PCPA on proliferation was transient. Despite depleting 5HT levels for 2 weeks, there was no significant alteration in BrdU- and Ki-67-labelled cells. These results showed that reducing 5 -HT by these methods did not result in robust changes in the numbers of proliferating cells in the dentate gyrus of the adult hippocampus, at least in the male Lister Hooded strain. While our results do not give substantial support to the idea that reduced 5-HT decreases proliferation in the dentate gyrus, the possibility that increasing its activity either by drugs that accentuate its action (eg SSRIs) or those that activate 5-HT receptors remains plausible (Radley and Jacobs, 2002; Santarelli et al, 2003). Control of cell proliferation by 5-HT may depend upon activating specific 5 -HT receptors, rather than by reducing global levels of 5-HT in the brain, since previous reports (Santarelli et al, 2003) have shown that fluoxetine enhanced neurogenesis via the 5-HT1A receptor. In confirmation of this, we have recently found that a $5-\mathrm{HT} 1 \mathrm{~A}$ agonist $(8-\mathrm{OH}-$ DPAT) increased cell proliferation in 5-HT-depleted animals (Huang \& Herbert unpublished observations).

After 14 days PCPA treatment, we did not detect differences in the plasma corticosterone level compared with control animals. By contrast, 5,7-DHT-depleted animals had higher levels of circulating corticosterone. HPLC showed that 2 weeks PCPA treatment decreased NA and DOPAC by about 30 and $44 \%$ (data not shown). It is known that NA depletion with DSP-4 or DA depletion by 6OHDA reduced basal corticosterone levels (Bakke et al, 1986; Casolini et al, 1993). Thus, the lowered plasma
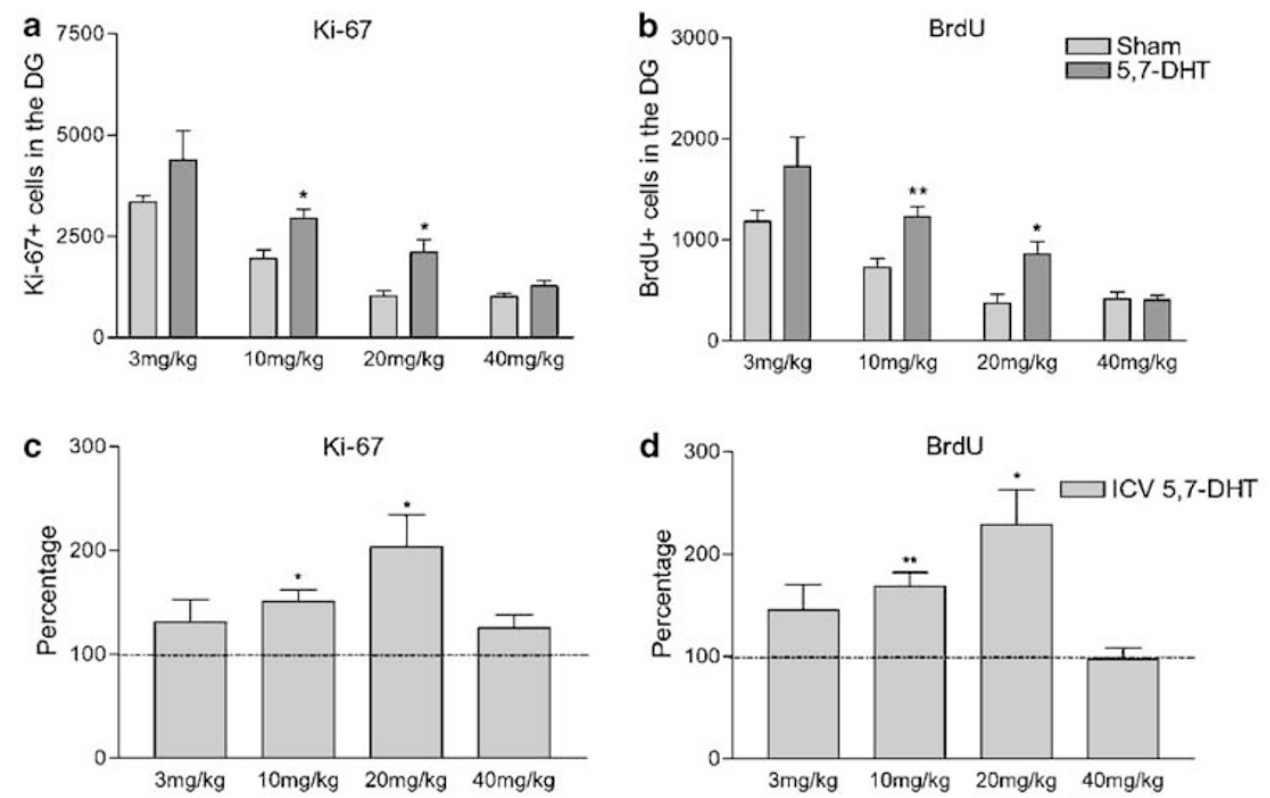

Figure 7 (a) Ki-67- and (b) BrdU-labelled cells in 5-HT-depleted (i.c.v. 5,7-DHT) or control rats, which were bilaterally adrenalectomized (ADX) I week later and then injected daily with corticosterone $(0,3,10,20$, or $40 \mathrm{mg} / \mathrm{kg})$ for 8 days. Animals depleted of 5-HT by 5,7-DHT and adrenalectomized but not given corticosterone did not survive $(0 \mathrm{mg} / \mathrm{kg}$ group). (c, d) The percentage of proliferation expressed as a proportion of the corresponding sham-depleted controls at each dose of corticosterone $\left(* p<0.05\right.$, ${ }^{*} * p<0.0$ l relative to sham-operated animals at the same dose). 
corticosterone in PCPA-depleted animals could have been caused by the reduction in NA and DOPAC levels. Nevertheless, results in the literature are inconsistent (Daniels et al, 1989) and the role of 5-HT depletion on corticosterone levels remains to be clarified.

Several previous findings, including our own data (Cameron and Gould, 1994; Karishma and Herbert, 2002), show that corticosterone has a major inhibitory effect on cell proliferation in the hippocampus of the adult rat (Experiment 4). However, Experiment 1 also showed that there were no changes in the number of proliferating cells in the dentate gyrus of 5-HT-depleted rats despite increased corticosterone levels. One explanation could be that 5-HT depletion modulated the response of the brain to corticosterone-induced changes in proliferation. This interpretation was encouraged by a previous report (Siegel et al, 1983) showing that 5,7-DHT depletion reduced the binding capacity of corticosterone in the hippocampus, which would also account for its lack of effect on proliferation. The next two experiments tested this proposition directly.

In Experiment 5, corticosterone levels were controlled by adrenalectomy followed by a subcutaneous pellet of corticosterone in conjunction with central 5-HT depletion by i.c.v. 5,7-DHT. For reasons that we do not understand, basal corticosterone levels were higher in implanted rats depleted of 5-HT (see below). This may be partially due to lowered body weight after 5-HT depletion. Despite this difference, there were no corresponding differences in proliferating cells assessed by either of the two methods we used. The crucial point is that additional injections of corticosterone were effective in reducing neurogenesis in 5HT intact rats with 'replacement' levels of corticosterone. However, they had no effect in 5-HT-depleted ones, suggesting that the latter were resistant to the effect of additional corticosterone. It should also be noted that plasma corticosterone was no different in the two corticosterone-supplemented groups.

This was explored further in a dose-response study. Animals were adrenalectomized (ADX) and given various doses of corticosterone replacement $(0-40 \mathrm{mg} / \mathrm{kg})$. Giving graded doses of corticosterone to ADX rats confirmed that 5-HT modulated the corticosterone-induced suppression of cell proliferation. It was unfortunate that 5 -HT-depleted rats without corticosterone supplementation did not survive, so we cannot know whether levels would have been altered after ADX by 5-HT depletion, although we can surmise that there would have been no difference. Nevertheless, this experiment demonstrated that 5 -HT depletion can reduce the suppressive effect of corticosterone at 10 and $20 \mathrm{mg} / \mathrm{kg}$; results at the lowest dose were in the same direction, but not significantly so, and at $40 \mathrm{mg} / \mathrm{kg}$ there seemed to be a 'floor' effect, such that proliferation was suppressed maximally in both 5-HT-depleted and control groups. The percentages (relative to shams) showed clearly that 5,7-DHT treatment decreased the sensitivity of proliferating cells to corticosterone. The fact that these results were most pronounced in the mid range of the corticosterone treatment suggests that 5-HT depletion desensitized the low-affinity corticosterone receptors (GR), but not the highaffinity mineralocorticoid receptors (MR), but this needs to be explored further. 5-HT increases GR, but not MR, densities in the cultured hippocampal neurons or fetal mouse hippocampus neurons (Mitchell et al, 1990; Erdeljan et al, 2001; Laplante et al, 2002). However, there is a report that 5,7-DHT lesions produced a regionally selective decrease in both hippocampal GR and MR mRNA expression (Seckl and Fink, 1991). These earlier results, obtained in quite different contexts, offer a plausible mechanism for the effects we describe in this paper. Another possibility is that depleting 5-HT might impair NMDA receptor functioning. Blockade of NMDA receptors by MK-801 has been shown to prevent the effect of corticosterone on neurogenesis (Cameron et al, 1998). Previous reports have also suggested that 5-HT may facilitate NMDA responses (Nedergaard et al, 1986, 1987; Mennini and Miari, 1991; Rahman and Neuman, 1993). However, the exact mechanism for the results reported in this paper remains to be established.

It should be noted that the protocol used in the last two experiments differed. In the first, additional corticosterone was give to adrenalectomized rats maintained at 'basal' levels by a subcutaneous corticosterone pellet. In the second, ADX rats were given graded doses of corticosterone. Despite these differences in format, which are reflected in the cell counts from the two experiments, the results of each support that of the other.

The plasma corticosterone levels in depleted groups were higher than in sham-operated animals at the lower doses of corticosterone injection ( 3 and $10 \mathrm{mg} / \mathrm{kg}$ ). As in the previous experiment, this was unexpected. It might indicate that 5-HT depletion alters either the absorption or clearance of corticosterone following s.c. injections. However, the body weights of 5-HT-depleted rats were about $50 \mathrm{~g}$ less than controls, which might have contributed, even though corticosterone doses were adjusted to take account of this difference. Despite the increased plasma corticosterone levels, Ki-67 and BrdU staining in the dentate gyrus of 5-HT-depleted rats were either similar to control groups or higher (not lower). This further reinforces the conclusion that sensitivity to corticosterone was reduced by 5-HT depletion as previously reported (Siegel et al, 1983). We were unable to measure corticosterone levels in CSF, hence we do not know whether higher plasma corticosterone is reflected in equivalently higher levels in the brain; however, on the basis of studies in humans, this would be expected to be the case (Guazzo et al, 1996).

Our conclusion is that reducing 5-HT also reduces the sensitivity of cell proliferation in the dentate gyrus to both endogenous and exogenously administered corticosterone. The mechanism for the interaction we show in this paper, and whether it also applies to other actions of corticoids in the brain, await further investigation.

\section{ACKNOWLEDGEMENTS}

This study was supported by a grant from the Wellcome Trust. GJ Huang received a grant from the Cambridge Overseas Trust. We thank Helen Shiers and Sarah Cleary for the assays and Dr Mark O'Connell for monoamine HPLC assays. 


\section{REFERENCES}

Altman J, Das GD (1965). Postnatal origin of microneurons in the rat brain. Nature 207: 953-956.

Azmitia EC, Liao B, Chen YS (1993). Increase of tryptophan hydroxylase enzyme protein by dexamethasone in adrenalectomized rat midbrain. J Neurosci 13: 5041-5055.

Bakke HK, Murison R, Walther B (1986). Effect of central noradrenaline depletion on corticosterone levels and gastric ulcerations in rats. Brain Res 368: 256-261.

Banasr M, Hery M, Brezun JM, Daszuta A (2001). Serotonin mediates oestrogen stimulation of cell proliferation in the adult dentate gyrus. Eur J Neurosci 14: 1417-1424.

Brezun JM, Daszuta A (1999). Depletion in serotonin decreases neurogenesis in the dentate gyrus and the subventricular zone of adult rats. Neuroscience 89: 999-1002.

Brezun JM, Daszuta A (2000). Serotonergic reinnervation reverses lesion-induced decreases in PSA-NCAM labeling and proliferation of hippocampal cells in adult rats. Hippocampus 10: 37-46.

Bush VL, Middlemiss DN, Marsden CA, Fone KC (2003). Implantation of a slow release corticosterone pellet induces long-term alterations in serotonergic neurochemistry in the rat brain. J Neuroendocrinol 15: 607-613.

Cameron HA, Gould E (1994). Adult neurogenesis is regulated by adrenal steroids in the dentate gyrus. Neuroscience 61: 203-209.

Cameron HA, McKay RD (2001). Adult neurogenesis produces a large pool of new granule cells in the dentate gyrus. J Comp Neurol 435: 406-417.

Cameron HA, Tanapat P, Gould E (1998). Adrenal steroids and $\mathrm{N}$ methyl-D-aspartate receptor activation regulate neurogenesis in the dentate gyrus of adult rats through a common pathway. Neuroscience 82: 349-354.

Casolini P, Kabbaj M, Leprat F, Piazza PV, Rouge-Pont F, Angelucci L et al (1993). Basal and stress-induced corticosterone secretion is decreased by lesion of mesencephalic dopaminergic neurons. Brain Res 622: 311-314.

Caspi A, Sugden K, Moffitt TE, Taylor A, Craig IW, Harrington H et al (2003). Influence of life stress on depression: moderation by a polymorphism in the 5-HTT gene. Science 301: 386-389.

Chalmers DT, Kwak SP, Mansour A, Akil H, Watson SJ (1993). Corticosteroids regulate brain hippocampal 5-HT1A receptor mRNA expression. J Neurosci 13: 914-923.

Chung KK, Martinez M, Herbert J (1999). Central serotonin depletion modulates the behavioural, endocrine and physiological responses to repeated social stress and subsequent c-fos expression in the brains of male rats. Neuroscience 92: 613-625.

Chung KK, Martinez M, Herbert J (2000). C-fos expression, behavioural, endocrine and autonomic responses to acute social stress in male rats after chronic restraint: modulation by serotonin. Neuroscience 95: 453-463.

Clark MS, Russo AF (1997). Tissue-specific glucocorticoid regulation of tryptophan hydroxylase mRNA levels. Brain Res Mol Brain Res 48: 346-354.

Daniels WM, Jaffer A, Searson A, Russell VA, Taljaard JJ (1989). The effect of partial noradrenergic denervation on corticosterone secretion in the rat. Neurochem Res 14: 1187-1190.

Erdeljan P, MacDonald JF, Matthews SG (2001). Glucocorticoids and serotonin alter glucocorticoid receptor (GR) but not mineralocorticoid receptor (MR) mRNA levels in fetal mouse hippocampal neurons, in vitro. Brain Res 896: 130-136.

Eriksson PS, Perfilieva E, Bjork-Eriksson T, Alborn AM, Nordborg C, Peterson DA et al (1998). Neurogenesis in the adult human hippocampus. Nat Med 4: 1313-1317.

Fairchild G, Leitch MM, Ingram CD (2003). Acute and chronic effects of corticosterone on 5-HT1A receptor-mediated autoinhibition in the rat dorsal raphe nucleus. Neuropharmacology 45: 925-934.
Gartside SE, Leitch MM, Young AH (2003). Altered glucocorticoid rhythm attenuates the ability of a chronic SSRI to elevate forebrain 5-HT: implications for the treatment of depression. Neuropsychopharmacology 28: 1572-1578.

Goodyer IM, Herbert J, Tamplin A, Altham PM (2000). Recent life events, cortisol, dehydroepiandrosterone and the onset of major depression in high-risk adolescents. $\mathrm{Br} J$ Psychiatry 177: 499-504.

Gould E, McEwen BS, Tanapat P, Galea LA, Fuchs E (1997). Neurogenesis in the dentate gyrus of the adult tree shrew is regulated by psychosocial stress and NMDA receptor activation. J Neurosci 17: 2492-2498.

Guazzo EP, Kirkpatrick PJ, Goodyer IM, Shiers HM, Herbert J (1996). Cortisol, dehydroepiandrosterone (DHEA), and DHEA sulfate in the cerebrospinal fluid of man: relation to blood levels and the effects of age. J Clin Endocrinol Metab 81: 3951-3960.

Harbuz MS, Chalmers J, De Souza L, Lightman SL (1993). Stressinduced activation of CRF and c-fos mRNAs in the paraventricular nucleus are not affected by serotonin depletion. Brain Res 609: 167-173.

Harris TO, Borsanyi S, Messari S, Stanford K, Cleary SE, Shiers HM et al (2000). Morning cortisol as a risk factor for subsequent major depressive disorder in adult women. Br J Psychiatry 177: 505-510.

Hemrick-Luecke SK ED (2002). Comparison of the potency of MDL 100,907 and SB 242084 in blocking the serotonin (5-HT)(2) receptor agonist-induced increases in rat serum corticosterone concentrations: evidence for $5-\mathrm{HT}(2 \mathrm{~A})$ receptor mediation of the HPA axis. Neuropharmacology 42: 162-169.

Karishma KK, Herbert J (2002). Dehydroepiandrosterone (DHEA) stimulates neurogenesis in the hippocampus of the rat, promotes survival of newly formed neurons and prevents corticosteroneinduced suppression. Eur J Neurosci 16: 445-453.

Kee N, Sivalingam S, Boonstra R, Wojtowicz JM (2002). The utility of Ki-67 and BrdU as proliferative markers of adult neurogenesis. J Neurosci Methods 115: 97-105.

Kempermann G, Gage FH (2002). Genetic determinants of adult hippocampal neurogenesis correlate with acquisition, but not probe trial performance, in the water maze task. Eur J Neurosci 16: $129-136$.

Kuroda Y, Watanabe Y, Albeck DS, Hastings NB, McEwen BS (1994). Effects of adrenalectomy and type I or type II glucocorticoid receptor activation on 5-HT1A and 5-HT2 receptor binding and 5-HT transporter mRNA expression in rat brain. Brain Res 648: 157-161.

Laplante P, Diorio J, Meaney MJ (2002). Serotonin regulates hippocampal glucocorticoid receptor expression via a 5-HT7 receptor. Brain Res Dev Brain Res 139: 199-203.

Leitch MM, Ingram $\mathrm{CD}$, Young $\mathrm{AH}$, McQuade R, Gartside SE (2003). Flattening the corticosterone rhythm attenuates 5-HT1A autoreceptor function in the rat: relevance for depression. Neuropsychopharmacology 28: 119-125.

Malberg JE, Duman RS (2003). Cell proliferation in adult hippocampus is decreased by inescapable stress: reversal by fluoxetine treatment. Neuropsychopharmacology 28: $1562-1571$.

Malberg JE, Eisch AJ, Nestler EJ, Duman RS (2000). Chronic antidepressant treatment increases neurogenesis in adult rat hippocampus. J Neurosci 20: 9104-9110.

McQuade R, Sharp T (1997). Functional mapping of dorsal and median raphe 5-hydroxytryptamine pathways in forebrain of the rat using microdialysis. J Neurochem 69: 791-796.

Meijer OC, de Kloet ER (1994). Corticosterone suppresses the expression of 5-HT1A receptor mRNA in rat dentate gyrus. Eur J Pharmacol 266: 255-261.

Mennini T, Miari A (1991). Modulation of $\left[{ }^{3} \mathrm{H}\right]$-glutamate binding by serotonin in the rat hippocampus: an autoradiographic study. Life Sci 49: 283-292. 
Mitchell JB, Rowe W, Boksa P, Meaney MJ (1990). Serotonin regulates type II corticosteroid receptor binding in hippocampal cell cultures. J Neurosci 10: 1745-1752.

Mueller NK, Beck SG (2000). Corticosteroids alter the 5-HT(1A) receptor-mediated response in CA1 hippocampal pyramidal cells. Neuropsychopharmacology 23: 419-427.

Murphy BE (1991). Steroids and depression. J Steroid Biochem Mol Biol 38: 537-559.

Nedergaard S, Engberg I, Flatman JA (1986). Serotonin facilitates NMDA responses of cat neocortical neurones. Acta Physiol Scand 128: 323-325.

Nedergaard S, Engberg I, Flatman JA (1987). The modulation of excitatory amino acid responses by serotonin in the cat neocortex in vitro. Cell Mol Neurobiol 7: 367-379.

Pariante CM, Makoff A, Lovestone S, Feroli S, Heyden A, Miller AH et al (2001). Antidepressants enhance glucocorticoid receptor function in vitro by modulating the membrane steroid transporters. Br J Pharmacol 134: 1335-1343.

Radley JJ, Jacobs BL (2002). 5-HT1A receptor antagonist administration decreases cell proliferation in the dentate gyrus. Brain Res 955: 264-267.

Rahman S, Neuman RS (1993). Activation of 5-HT2 receptors facilitates depolarization of neocortical neurons by $N$-methyl- $D$ aspartate. Eur J Pharmacol 231: 347-354.

Ramaley JA (1973). The development of daily change in serum corticosterone in pre-weanling rats. Steroids 21: 433-442.

Sachar EJ (1975). Twenty-four-hour cortisol secretory patterns in depressed and manic patients. Prog Brain Res 42: 81-91.

Santarelli L, Saxe M, Gross C, Surget A, Battaglia F, Dulawa S et al (2003). Requirement of hippocampal neurogenesis for the behavioral effects of antidepressants. Science 301: 805-809.
Scholzen T, Gerdes J (2000). The Ki-67 protein: from the known and the unknown. J Cell Physiol 182: 311-322.

Seckl JR, Fink G (1991). Use of in situ hybridization to investigate the regulation of hippocampal corticosteroid receptors by monoamines. J Steroid Biochem Mol Biol 40: 685-688.

Siegel RA, Weidenfeld J, Chen M, Feldman S, Melamed E, Chowers I (1983). Hippocampal cell nuclear binding of corticosterone following 5,7-dihydroxytryptamine. Mol Cell Endocrinol 31: 253-259.

Tagliaferro P, Ramos AJ, Lopez EM, Pecci Saavedra J, Brusco A (1997). Neural and astroglial effects of a chronic parachlorophenylalanine-induced serotonin synthesis inhibition. $\mathrm{Mol}$ Chem Neuropathol 32: 195-211.

Tanapat P, Hastings NB, Reeves AJ, Gould E (1999). Estrogen stimulates a transient increase in the number of new neurons in the dentate gyrus of the adult female rat. J Neurosci 19: 5792-5801.

Temel Y, Helmy A, Pinnock S, Herbert J (2003). Effect of serotonin depletion on the neuronal, endocrine and behavioural responses to corticotropin-releasing factor in the rat. Neurosci Lett 338: 139-142.

Timmer RF (1962). Changes in corticosterone levels after severe stress in the rat. Proc Soc Exp Biol Med 110: 694-697.

van Riel E, Meijer OC, Steenbergen PJ, Joels M (2003). Chronic unpredictable stress causes attenuation of serotonin responses in cornu ammonis 1 pyramidal neurons. Neuroscience 120: 649-658.

Wato M, Nishikawa T, Fujita A, Nagao Y, Tsujimoto K, Matsuoka $\mathrm{K}$ et al (1993). Application of in vitro bromodeoxyuridine labeling of oral cancers. J Osaka Dent Univ 27: 113-120. 